\title{
National minorities and their representation in social surveys: which practices make a difference?
}

\author{
Francesco Laganà • Guy Elcheroth • Sandra Penic • \\ Brian Kleiner • Nicole Fasel
}

Published online: 29 September 2011

(C) Springer Science+Business Media B.V. 2011

\begin{abstract}
This paper presents a systematic study of survey mechanisms that produce or reduce minority bias in social surveys. It extends the work of Lipps et al. (2011) who have demonstrated that, in the Swiss context, the more an ethno-national minority community differs, socio-culturally and socio-economically, from the national majority, the less it is likely to be represented in its proper proportion in the major national surveys. Minority bias furthermore has a vertical dimension: socio-economic bias against individuals from the most deprived backgrounds becomes extreme within ethno-national minority communities. Using data from the Swiss Labour Force Survey, the Swiss Household Panel, and the Swiss sample of the European Social Survey, in the present work we empirically assess the impact of three types of survey practices on minority bias: (1) strategies to increase overall response rates of the whole population indiscriminately from its minority status, (2) the use of preand post-stratification measures that take into account the overall share of foreigners in the national population, and (3) the conduct of interviews in a wider range of languages, in order to facilitate survey response among certain (linguistic) minorities. Our findings show that
\end{abstract}

F. Laganà $(\varangle) \cdot$ G. Elcheroth $\cdot$ S. Penic

Life Course and Inequalities Research Center (LINES), Institute of Social Sciences,

University of Lausanne, Bâtiment Vidy, 1015 Lausanne, Switzerland

e-mail: francesco.lagana@unil.ch

G. Elcheroth

e-mail: guy.elcheroth@unil.ch

S. Penic

e-mail: sandra.penic@unil.ch

F. Laganà $\cdot$ B. Kleiner

FORS - Swiss Centre of Expertise in the Social Sciences,

Bâtiment Vidy, 1015 Lausanne, Switzerland

B. Kleiner

e-mail: brian.kleiner@fors.unil.ch

N. Fasel

Department of Social Psychology, University of Lausanne, Bâtiment Vidy, 1015 Lausanne, Switzerland e-mail: nicole.fasel@unil.ch 
efforts to increase overall response rates can, paradoxically, create even more minority bias. On the other hand, they suggest that a combination of stratified sampling and a wider range of survey languages can have a positive effect in reducing survey bias, both between and within national categories. We conclude that measures that take into account and adapt to the social and cultural heterogeneity of surveyed populations do make a difference, whereas additional efforts that only replicate existing routine practices can be counter-productive.

Keywords Survey Methodology $\cdot$ Sampling bias $\cdot$ Ethno-national minorities $\cdot$ Response rates $\cdot$ Survey languages $\cdot$ Stratified sampling

\author{
Abbreviations \\ SLFS Swiss Labour Force Survey \\ SHP Swiss Household Panel \\ ESS European Social Survey
}

\title{
1 Introduction and overview
}

During the last decades, processes of globalisation have led to an increase in both the magnitude and diversity of migration flows toward Western countries (see Castles and Miller 1993; Koser and Lutz 1998). As a consequence, many Western European societies in particular display growing linguistic, ethnic, and cultural heterogeneity. Nowadays, this tendency is accompanied throughout an increasing number of host countries by pervasive public discourse about "new" social problems related to immigration and integration issues. For representative survey research, this contemporary background generates two inter-related challenges: on the one hand, to build an empirical knowledge-base for the study of social dynamics within culturally diversified contexts (a pivotal concern for social scientists), and on the other hand, to gather data that allow computing of accurate social indicators, with regard to the situation of the entire population (a pivotal concern for official statistics). A correct representation of ethno-national minorities in social surveys is a fundamental condition to meet both types of challenges. However, the literature shows that ethnic minorities may not be accurately represented. There are, systematically, higher non-response rates in cross sectional surveys (see Feskens et al. 2007 for the Netherlands; Deding et al. 2008 for Denmark) due to fewer contacts and more refusals (Nielsen and Pedersen 2000; Camarota and Capizzano 2004; Jakobsen 2004; Eisner and Ribeaud 2007), as well as higher attrition rates in longitudinal surveys (Peracchi and Depalo 2006).

Recently, a multi-disciplinary working group has started to investigate this issue in Switzerland as well. This group scrutinises three major surveys that inform official statistics or social scientific research: the Swiss Labour Force Survey (SLFS), the Swiss Household Panel Survey (SHP), and the European Social Survey in Switzerland (ESS). The present work pursues the line of research started by Lipps et al. (2011) who have described social factors and cleavages that structure bias across national minorities in Switzerland. More specifically it tries to open the black box of survey processes and practices that can produce, amplify, or redress such biases. Therefore, before we explain the goals and questions that have oriented the present work, let us first review the key findings that constitute our starting point.

Lipps et al. (2011) have highlighted that, on average, nationwide Swiss surveys are systematically and strongly biased against the fifth of the countries' population that does not hold Swiss citizenship. At the same time, these analyses demonstrated that, as far as survey 
participation is concerned, there is no such thing as a homogenous population of foreigners in Switzerland. Nationals from the linguistically, economically, and socially similar neighbouring countries are generally well represented in Swiss surveys. But large minority groups, such as nationals from the area of former Yugoslavia or Turkey, are dramatically underrepresented. In addition to strong heterogeneity between national categories, there also appears to be important heterogeneity within these categories: under-representation tends to be the most pronounced for members of national minorities with lower levels of education. The authors further found a significant interaction between educational attainment and nationality on attrition in longitudinal surveys: the difference in attrition rates between Swiss and national minorities is greatest for the least educated. But these analyses also showed that under-representation of national minorities cannot be reduced to the sole issue of education or social class.

In fact the authors found that, overall, social class-identified by individuals' occupations - only very partially mediates the large differences in non-response or attrition between Swiss citizens and members from certain national minority groups. Hence, we need to look for other explanatory factors that may account for the specific exclusion from national surveys of socially disadvantaged members of communities from former Yugoslavian, Turkish, or, more generally, non-western European origin. This is what the present work aims to contribute: a systematic analysis of survey practices that produce or reduce bias against minority communities as a whole, and against the most vulnerable layers within these communities, in particular.

Switzerland represents an interesting site, within the larger Western European context, to study survey practices in a culturally diversified society. In fact, the tendency toward diversification, stratification, and polarisation of the migration process (Castles and Miller 1993) is particularly pronounced here. For historical and socio-economic reasons, Switzerland has been characterized by two kinds of migrations: on the one hand, a highly skilled migration from northern Europe and, on the other hand, unskilled migrations from Italy in the 50s, Spain in the 60s, and Portugal and Ex-Yugoslavia in the 80s and early 90s (Piguet 2004). In addition, the new legislative frame on Swiss immigration policies further accentuates the heterogeneity of inward migration flows (Gross 2006).

1.1 Research goals: why do we need to know more about survey practices that affect minority bias?

Let us now stress the main reasons why the findings of Lipps et al. (2011) should not leave us indifferent, but rather should urge us to have a closer look on the mechanisms that lead to the under-representation of certain national minorities. First of all, there are direct consequences for the interpretation of official national statistics. Many social indicators are meant to reflect the situation of vulnerable populations in a country, either directly—such as poverty rates and various social exclusion indices-or indirectly, such as inequality and development indices, which are sensitive to the number of cases at the bottom of a given distribution of prosperity or well-being. Rather obviously, there is a problem when these indicators are based on survey data that exclude large segments of the socially disadvantaged population of non-western European origin-i.e., a numerically important part of the residential population, which is particularly at risk.

There are only two options for social statisticians to handle such a situation, and both are less than optimal. One is to ignore the biased composition of the sample and to make straightforward inferences from the distribution of survey responses to the reality of the population. This will inevitably result in too conservative estimates of poverty or inequalities, and in statistics that embellish social reality rather than reflect it. The other option is to 
carry out some kind of posterior adjustment of the data and give more weight to the survey responses from participants that belong to an under-represented social category than to those that belong to a well- or even over-represented category. As a means to redress the bias of interest here, such procedures thus attempt to use information available on a participating minority within the minority, in order to correct for the absence of the many who did not participate. This implies at least two critical assumptions: (a) that the categories used to weight the data are defined appropriately to catch the relevant cleavages along which inclusion in versus exclusion from the survey process actually operates, and (b) that within each category participating members are equivalent to non-participating members (at least with regard to relevant variables). If we want these procedures (at least for any descriptive purposes) of data adjustment to become a scientific practice, then we need scientific knowledge about the circumstances under which the two assumptions apply.

Once we have arrived at this point, we have already encircled the second reason to study the mechanisms that lead to minority bias: acknowledging the phenomenon not only highlights the necessity to handle its consequences, but also creates the opportunity to learn more about the dynamics of sampling and surveying in general.

National minorities' under-representation in social surveys can be conceived of as the consequence of a "failure" in one of the steps in the process of gaining respondent survey selection and participation. Interestingly then, by revealing what surveys are unable to achieve, minority bias can teach us something about the way they work. For example, effective survey processes are likely to rely on a series of implicit assumptions about seemingly trivial things like residential arrangements and daily routines, meaningful interactions and legitimate requests, relevant incentives and appropriate behaviour. Cumulative experiences of survey researchers and interviewers might have well calibrated these assumptions, and the practices they inform, for the majority of the population. But nevertheless - or even precisely for this reason-the same set of assumptions can be rather disconnected from the social reality experienced by various minority groups within the same population. As we will further develop in the remainder of this paper, this conceptual perspective will actually help us to draw a line between "remedies" that are likely to make a difference with respect to minority bias and those that will not.

\subsection{Research questions}

Bearing these goals in mind, we designed the present research to clarify how minority bias relates to three different types of survey practices: (a) efforts to enhance overall response rates, (b) pre-and post-survey stratification and, (c) the increase of linguistic plurality. For each of these relationships, we sought to address a pair of operational research questions.

Although overall high response rates are generally thought of as a necessary condition for representative samples, the issue of how response rates precisely relate to survey bias is still controversial. In a state of the art synthesis, Groves (2006) found meta-analytical evidence for a moderate positive correlation only (of 0.33 ), between nonresponse rates and nonresponse bias across 30 different methodological studies and 235 different variables. Important for our own research perspective, the author noted that the "vast majority of variation in relative nonresponse bias lies within surveys, not among them" (p. 659). In other words, if high response rates do go hand in hand with the reduction of some biases, this does not imply that they constitute a magic solution for all, or even most, types of biases (given that $100 \%$ response rates are never obtained and even rarely approached). In particular, it is at least premature to 
exclude that minority bias could fall into the category of biases that resist (relatively) high response rates.

Furthermore, higher response rates are not obtained spontaneously: they require additional efforts and resources. Non-contact rates can be diminished by increasing the numbers of calls or visits, refusal rates by re-contacting non-respondents in order to "convert" them into respondents. In an insightful experiment, Peytchev et al. (2009) found, however, that a higher number of calls resulted in less survey bias only when associated with changes in survey protocols. Additional efforts paid off when something else could be proposed to initial non-respondents (a shorter questionnaire, more incentives...). Conversely, keeping the survey protocol the same resulted in recruiting the same type of respondents-and hence in reproducing the same biases - even with more efforts and higher overall response rates.

The pessimistic assumption that more of the same practices will not result in different outcomes can thus be opposed to the optimistic assumption that more efforts pay off, even when it comes to reducing specific biases. In addition, differences between individual interviewers provide an interesting angle to push further the investigation of the "more-of-the-same" problem. It is common sense among survey researchers that more experienced interviewers should have developed more skills to recruit respondents and hence produce higher response rates. For example, analysing interviewer effects in the ESS, Lipps and Pollien (2011) found that more experienced or more senior interviewers had better performances in terms of overall response rates than newcomers. At the same time, when interviewers have been socialised within a given survey environment for a longer period of time, they are more likely to internalise any standard practices, including practices that create minority bias so systematically in surveys. Then, again, we can oppose the pessimistic view that more experienced interviewers will be the most likely to reproduce more of the same practices and biases, to the optimistic assumption that experience leads to better skills and performances. Two questions for empirical investigation can thus be kept at this stage:

Question 1: Do additional efforts to establish contact or convert reluctant respondents result in less minority bias?

Question 2: Are more experienced interviewers more capable of reducing minority bias?

The next pair of questions addresses the relationship between minority bias and survey stratification, which can intervene both before and after data collection. Post-stratification has become a standard survey practice, which derives both its advantages and weaknesses from the fact that it does not influence the fieldwork itself. As a consequence, costs are minimal, and suboptimal solutions will not affect the quality of the data, only of outcome of specific analyses of these data. On the other hand, there are at least two things that post-stratification weights can never achieve: they are unable to redress bias against a group of people as long as these people are (almost) completely absent from the dataset and/or as long as the group is not recognised as such when post-stratification weights are computed. As the aim of the present work is to describe routine practices rather than to prescribe ideal practices, we will focus here on the most commonly used post-stratification weights and assess how (neglect of) minority bias affects the population structure that underlies most prominent survey findings in Switzerland.

Next, we will have a closer look at, to our knowledge, the only instance of a major regular Swiss survey that stratifies the sample by the main national categories before data collection: the SLFS foreigner sample. Evidently, such ambitious sampling procedures solve the problem of unequal representation across national categories. But what will be their impact on unequal representation within national categories? As Lipps et al. (2011) have shown, the most striking consequence of minority bias is that the minority bias is mostly concentrated 
among socially disadvantaged respondents of non-western European countries. Will unequal representation of socio-economically defined subgroups within non-western European communities even be exaggerated when high pressure on interviewers to fulfil the target size of the national strata, leads them to concentrate their efforts on the "easiest" recruits within each nationality? Or will the confrontation of interviewers with a critical mass of members of a national community facilitate a learning process, and eventually enable them to communicate more efficiently, even with socially disadvantaged members of the same community? To summarise both issues, then:

Question 3: Do institutionalised weighting procedures result in statistical estimates free of minority bias?

Question 4: Does the correction of bias between national categories, by way of stratified sampling, also affect bias within national categories (either positively or negatively)?

Finally, we will address the rather straightforward issue of whether it makes a difference when surveys are offered in the native languages of respondents. Again, the SLFS has been holding a distinctive place among regular national surveys, since it progressively increased the number of survey languages from three to eight over the last decade. Normally, one would expect this costly measure to result in better representation of those minority groups that were part of recent immigrations from countries without a national language in common with the host country, such as Turkish or former Yugoslavian communities in Switzerland. Furthermore, there is an expectation that linguistic barriers are more difficult to surpass for individuals with less social and educational resources and, hence, that removing these barriers should also result in less bias within national categories. As we will study these issues both cross-sectionally and longitudinally, the last pair of questions can be formulated as follows:

Question 5: Do more survey languages help to recruit members from minority groups, in particular among the socially disadvantaged?

Question 6: Do more survey languages help to keep (socially disadvantaged) members from minority groups in the sample for longitudinal studies?

\subsection{Research strategy}

\subsubsection{How did we choose data sources and analytical approaches?}

Data from three pre-eminent national surveys served as the empirical basis to our analyses: the SLFS, the SHP and the Swiss part of the ESS. These surveys share the goal of providing data that are representative of the country's resident population, by way of rigorous probability sampling. Each of them devotes considerable effort and high-level methodological monitoring to achieve this goal. They are all part of different prestigious international research programs and networks, aiming to ensure comparable and high-quality data across Europe, and beyond. By focusing on these three leading surveys, our goal was not to blame particular projects for neglecting the issue of minority bias, but to show that the problem is so pervasive that we can easily find it even when considering survey research at its best.

The other reasons that motivated our choice have more to do with what distinguishes each of the three surveys than with what they have in common (see Appendix Table 1 for detailed comparative information on the main characteristics of the three surveys). The SLFS, which is conducted yearly since 1991 by the Swiss federal statistical office and focuses on income and working conditions, and the SHP, launched in 1999 as a joint academic and administrative initiative to provide a more comprehensive data source on the dynamics of living conditions, 
are pivotal to the construction of official social statistics both directly (as the SLFS) and indirectly (as the SHP). Both provide post-stratification weights to enhance the accuracy of population-level inferences based on these datasets. Micro-data users of the SLFS even have to commit themselves legally to publish only indicators based on weighted data-a striking illustration of the federal administration's faith in these weights. For a relevant test of the impact of the minority bias, not only on survey data, but on survey outcomes that matter, these two surveys are essential, and the cross-sectional weights provided with the survey data allow us to address Question 3. Furthermore, as mentioned in the previous section, SFLS is unique both because of the stratified foreigner sample introduced in 2003 (relevant for Question 4), and because of the language experiment started the same year (relevant for Questions 5 and 6). A final interesting feature common to the two surveys is their longitudinal design: while SHP is a fully-fledged yearly panel study, SLFS includes a five-year rotating panel. As a consequence, these datasets allow us to study minority biases not only in cross-sectional survey inclusion/exclusion, but also in survey retention/attrition.

Our choice to further broaden investigations to the ESS was above all motivated by the fact that this survey has incorporated the single most important national initiative to increase response rates. Conducted bi-annually since 2002, this comparative survey on social conditions and social attitudes is a good example of an international survey which closely monitors national response rates and strongly encourages national research teams to implement measures to increase response rates. Setting an ambitious $70 \%$ target rate, the international guidelines to this survey are in line with a classic assumption of survey research: as nonrespondents distort random selection procedures, fewer non-respondents should imply fewer distortions and hence bring surveys closer to ideal conditions of unbiased probability sampling. In Switzerland, after a "bad start" in 2002 (an overall response rate of $34 \%$ at the bottom of the international ranking), a series of rather expensive measures were implemented during the following waves to bring response rates closer to the target, including virtually endless attempts to establish contact, specific strategies to convert non-cooperative eligible, and more work carried out by more experienced interviewers. These measures had a clear effect: for the three subsequent waves, response rates near $50 \%$ were observed, which is remarkably high for the Swiss context. This survey therefore provides a privileged opportunity to test empirically whether such (relatively successful) measures to improve response rates actually lead to less biased samples - and to answer Questions 1 and 2. Additionally, ESS data brought along their own specific asset: the availability of particularly well-documented contact and interviewer data, which allowed for much more detailed analyses of the impact of survey effort than what was attainable in the case of the other two surveys.

\subsubsection{Indicators of minority bias}

While minority bias is the common construct motivating all of our analyses, the concrete operationalisation of "bias" had to be accommodated flexibly to the opportunities and constraints inherent to each individual dataset. The foremost overall limitation set to our work stems from the absence (so far) of a nationwide Swiss population registry. As telephone and/or building registers were used as sampling frames in all three surveys, information on nationality or class background of non-respondents is systematically lacking. As a consequence, we could assess minority bias only indirectly, through a comparison between the population structure according to census data, on the one hand, and survey data, on the other hand.

We estimated the magnitude of cross-sectional bias by dividing the odds of a randomly selected individual in the sample to be part of a specific (sub)category by the odds of a randomly selected individual in the population to be part of the same (sub)category. 
Thus, the measure used is an odds ratio. The advantage of calculating odds as an indicator of bias - as compared to differences between percentages, for example — is that they are independent from marginal distributions. To distinguish bias that affects a given ethno-national minority community as a whole from the bias affecting a given social subcategory within the ethno-national community, we computed two types of indicators: bias between national minorities and bias within national minorities.

The bias between national minorities is defined as the ratio between the odds of a selected individual to be part of a national minority in the survey and the respective odds in the population. Let therefore be $j$ a national category, $s_{j}$ and $n$ respectively the sample size for this national category and the overall sample size for the survey. Furthermore, let $C_{j}$ be the population size for national category $j$ and $N$ the overall population size (according to census data). The between bias for the national category $j$ is estimated as follows:

$$
\text { Between_Bias }_{j \mid n}=\frac{\left[s_{j} /\left(n-s_{j}\right)\right]}{\left[C_{j} /\left(N-C_{j}\right)\right]}
$$

Sometimes, the interest lies more in comparing one national category to another, e.g., a particular national minority to the national majority group. When this was the goal of the analyses, we used Eq. 2 to compute an indicator of relative bias, where the sample size $s_{j}$ and population size $C_{j}$ of a national category $j$ (e.g., nationals from the former Yugoslavia) is compared to the sample size $s_{k}$ and population size $C_{k}$ of a reference category $k$ (e.g., Swiss nationals). Please note that this indicator includes an estimate of the gross sample size (ngross), which can be computed when sufficiently detailed contact data are available to determine the total number of eligible units in the initial sampling frame (that can be a list of addresses). In Eq. 2, $\frac{C_{j}}{N}$ stands for the population share of the national minority and $\frac{C_{j}}{N}$ ngross provides an estimate of the number of members of the national category $j$ that would be in an unbiased gross sample. The resulting indicator of relative bias thus expresses the ratio between the odds of a member of the national reference category $k$ to be included in the net sample, and the corresponding odds of a member of the national minority category $j$ :

$$
\text { Relative_Bias } s_{k \mid j}=\frac{s_{k} /\left(\frac{C_{k}}{N} \text { ngross }-s_{k}\right)}{s_{j} /\left(\frac{C_{j}}{N} \text { ngross }-s_{j}\right)}
$$

The bias within a given national minority is defined as the ratio between the odds of a randomly selected individual to be part of the social subcategory $i$ of the ethno-national minority community $j$ in the sample, and the corresponding odds in the population. Therefore, let $j$ be a national category (e.g. former-Yugoslavs) and $i$ a specific category of the interest variable (e.g. respondents with elementary education), $s_{i j}$ the number of sample cases that fall into the resulting subcategory (e.g. number of former-Yugoslav with low levels of education) and $C_{i j}$ the corresponding number of cases in the population. Let $n_{. j}$ and $N_{. j}$ further be the overall sample size respectively in the survey and the population value registered in census for the national minority $j$. The within bias is estimated as follows:

$$
\text { Within_Bias } s_{i j \mid j}=\frac{\left[s_{i j} /\left(n_{. j}-s_{i j}\right)\right]}{\left[C_{i j} /\left(N_{. j}-C_{i j}\right)\right]}
$$

To have an estimation of the overall bias against a socially and ethno-nationally defined sub-category, we need to combine within-bias toward the subcategory within an ethno-national 
community and between-bias affecting this community as a whole. The indicator of overall bias is therefore given by the product of the two types of bias mentioned in the formulas above.

$$
\text { Bias }_{i j \mid n}=\frac{\left[s_{i j} /\left(n_{. j}-s_{i j}\right)\right]}{\left[C_{i j} /\left(N_{. j}-C_{i j}\right)\right]} \times \frac{\left[s_{j} /\left(n-s_{j}\right)\right]}{\left[C_{j} /\left(N-C_{j}\right)\right]}
$$

Using the general formula presented in Eq. 4 it is possible to estimate all three types of bias: (a) bias between national categories-when we fix within bias to 1, (b) bias within a given national minority - that we obtain by fixing between bias to 1, and (c) the interaction between the two kinds of biases, that gives us an estimation of the overall bias with respect to the total population.

The obtained value is then a product between odds ratio. Since the odds ratio can vary between 0 and $+\infty$ and is equal to 1 when the two odds (in the census and in the survey) are equal, we will have an asymmetric distribution for under- and over-representation. For this reason, we also rescaled odds ratio to a logarithmic distribution. The overall bias formula presented in Eq. 4 can be redefined as follows:

$$
\ln \left(\text { Bias }_{i j}\right)=\ln \left(\frac{\left[s_{i j} /\left(n-s_{i j}\right)\right]}{\left[C_{i j} /\left(N-C_{i j}\right)\right]}\right)+\ln \left(\frac{\left[s_{j} /\left(n-s_{j}\right)\right]}{\left[C_{j} /\left(N-C_{j}\right)\right]}\right)
$$

As explained before the two terms of the equation identify respectively the within and the between bias. We can derive from this formula that a value of 0 in the two terms indicates that the sample share of the educational subcategory equals its population share (i.e., there is no bias), whereas values below 0 indicates that the subcategory is under-represented in the sample, and values above 0 that it is over-represented. ${ }^{1}$

The limitation that we found in modelling the bias did not apply for the study of bias in attrition processes in SHP and SLFS, which made the longitudinal approach an even more valuable complement to our work because it allows for fine-grained analyses of the individual correlates of survey participation. In this case, the method that we used to analyse under-representation is the binomial logistic regression.

\subsubsection{Variables used in the analyses}

The use of different surveys and the need of harmonization to make them comparable with the census data obliged us to be flexible in the recoding and definition of variables. In the present section we focus on the main variables and recoding used throughout all the analyses (cross-sectional and longitudinal).

The classification used to distinguish between different types of national minorities considers criteria of geographical, linguistic and cultural proximity with the Swiss group (relevant for the Italian, French and German minority), the historical importance in the process of immigration to Switzerland (Spanish, Portuguese, Turkish, Former-Yugoslavs and Albanian), and geographical distance for the groups constituting the residual component of immigration, coming from the rest of Europe, Americas, Africa and Asia, or Oceania. Dependently on data characteristics and surveys sample sizes, these groups have been aggregated into larger categories in order to allow for more robust analyses. However in all the analyses we kept the

\footnotetext{
${ }^{1}$ Equations 4 and 5 differ only in the scale on which the bias is estimated. This difference becomes more relevant when confidence intervals are generated to identify the degree of uncertainty of our bias estimates. Computing the confidence intervals in the logarithmic scale allows us to have symmetric estimates of bias precision, which is not possible when confidence intervals are estimated in the natural scale.
} 
Former-Yugoslavs and Albanian-who represent the main national minority in Switzerland, in terms of language and social vulnerability — as a separate category.

Education has been recoded into three levels (No education/Secondary I, Secondary II, Tertiary). Individuals who are still in training were classified in a fourth, residual category (whose results, being marginal for our analyses, are not presented here).

As in Lipps et al. (2011), the effect of social class, used as a control variable in the analysis of language plurality and attrition, is measured by the International Standard Classification of occupations. We recoded the first three one-digit categories of ISCO classification into the main category "Higher non manual", the categories 4 and 5 into "Lower non manual" and finally the categories 6, 7, 8, and 9 into the category of "Manual occupations. Additionally, in order to include in the analyses also those who are not employed, we gathered in one category (not in labor force) the non-active and the unemployed.

\section{Procedures and findings}

2.1 Minority bias and strategies to enhance responses rates in the European Social Survey in Switzerland

To address Question 1, we analysed contact data from four waves of the ESS in Switzerland, conducted between 2002 and 2008. The key variable of these analyses, national affiliation, could easily be established for respondents, by matching contact and response data. The corresponding survey items first distinguish between Swiss citizens and foreigners. Among the latter, one national affiliation was recorded (which implies that bi-national respondents had to choose which nationality to report), and allowed us to categorise foreigners into three categories: nationals from neighbouring countries (France, Germany, Austria, Liechtenstein and Italy), nationals from one of the countries of the former Yugoslavia or Albania, and a residual category including nationals from all other countries. In order to allow for sufficiently large sample sizes for minority groups, contact data were aggregated across the four waves of the Swiss ESS, resulting in a total number of 18.008 estimated eligible and 7.767 respondents, of whom 959 belonged to a national minority (i.e., did not have Swiss citizenship at the time of the survey).

ESS contact data include detailed information on the outcomes of each single attempt to establish contact with a target respondent. As shown in Fig. 1, these data allow simulating response rates for different categories of target respondents, as a function of the number of attempts to establish contact. These findings clearly illustrate the importance of numerous visits or phone calls in order to achieve optimal response rates. For example, if the instruction had been to stop efforts to establish contact or cooperation after three attempts, overall, response rates would only have been about half as high as they have been in effect under the demanding ESS fieldwork conditions. It is not exceptional that a respondent could still be included in the sample even after ten or more unsuccessful attempts had already been made before at the same address. But the same findings also suggest that the payoff of these efforts varies across different national categories. While response rates for Swiss citizens steadily raise and only reach their limit—close to 50\%, around the twentieth attempt to establish contact-response rates hit a ceiling earlier and dramatically lower-at only $15 \%$-for nationals from the former Yugoslavia or Albania.

Overall, it looks as if the "closer" (which can be read here as geographic, linguistic, or economic closeness) a national category comes to the national majority, the higher its selection probability in the sample and the more likely it is to benefit from supplementary efforts 


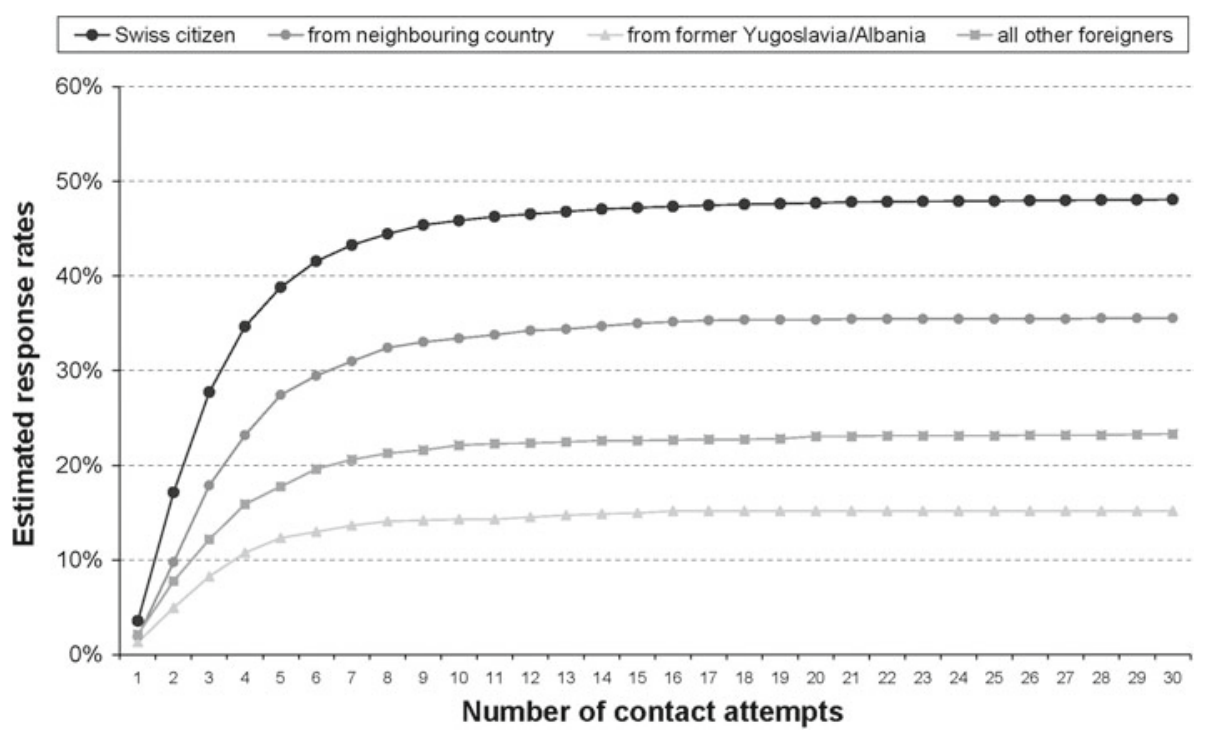

Fig. 1 Estimated cumulative response rates for four waves of ESS in Switzerland (2002-2008), by number of attempts to establish contact or cooperation, and citizenship of target respondents

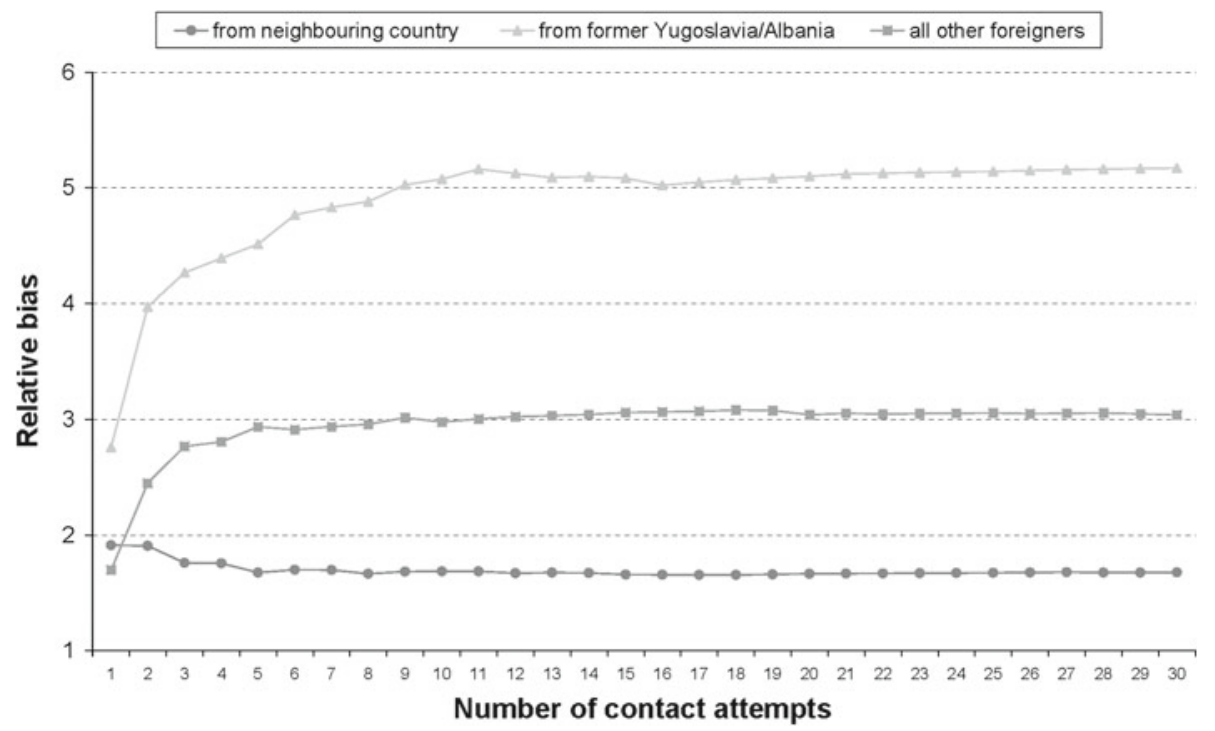

Fig. 2 Estimated relative sampling bias for four waves of ESS in Switzerland (2002-2008), by number of attempts to establish contact and citizenship of target respondents

to establish contact or cooperation. This impression is further corroborated by Fig. 2, which represents the same information under the form of (cumulative) relative bias: the odds of a Swiss citizen to be included in the sample after a given number of efforts, divided by the corresponding odds for three different categories of foreigners (following Eq. 2). Only in one case does the bias diminishes with increasing efforts: between the second and the fifth attempt 


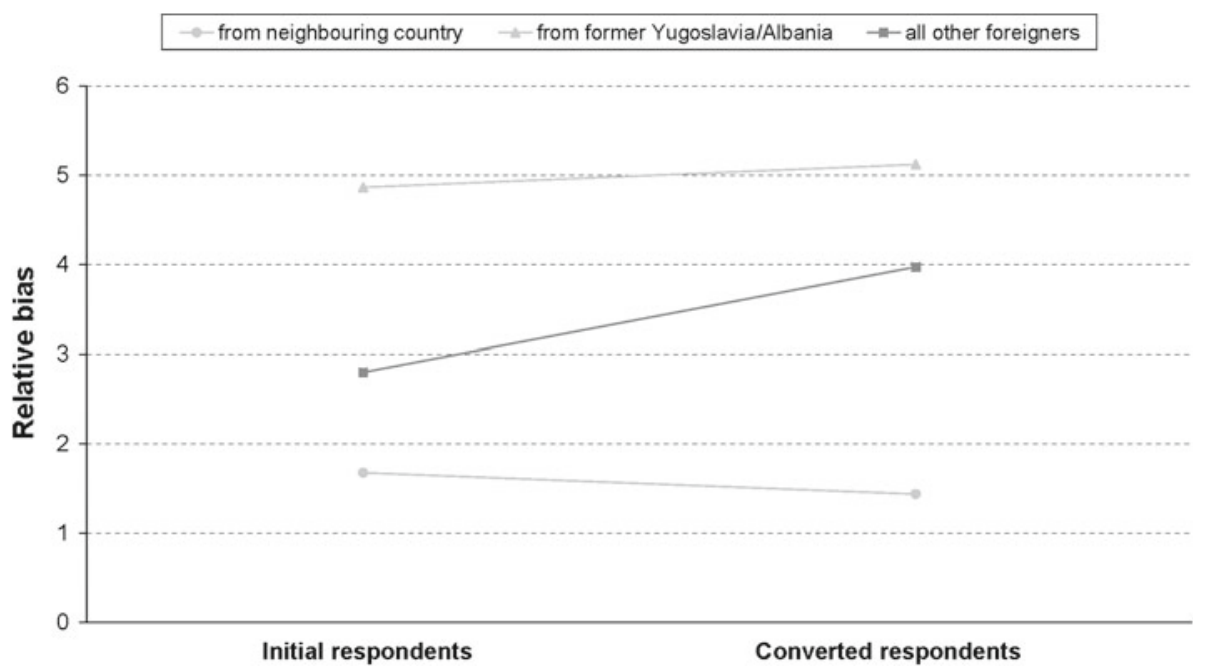

Fig. 3 Estimated relative sampling bias for four waves of ESS in Switzerland (2002-2008), respondents cooperating at first request and converted respondents, by citizenship

to establish contact, the odds of nationals from neighbouring countries come slightly closer to those of Swiss citizens. At the opposite end, unfavourable odds ratios for nationals from the former Yusgoslavia/Albania steadily increase and reach a peak after 11 attempts. Under such high effort conditions, ironically, bias against this minority group becomes extreme and their odds to be included in the sample are five times lower than the odds of Swiss citizens.

More specifically, it appears that an increase in contact attempts from 5 to 10 (which roughly corresponds to the difference between standard and demanding fieldwork), benefits more or less equally to all other categories, but substantially less to this particularly underrepresented minority group.

Further analyses focussed on the specific effects of attempts to convert eligible individuals who did not want to cooperate at a first request. Figure 3 compares estimated sampling bias for the three categories of foreigners, between respondents who cooperated at first request- the level of bias that would have been obtained if no conversion strategy had been implementedand converted respondents, who cooperated at a second, third, fourth, or even fifth request only. In order to control for the fact that bias among initial respondents results in a disproportionately high number of foreigners being left in the frame from which individuals are drawn for a second request, numbers of previous recruits within each category were subtracted from the corresponding numbers of estimated eligible before calculating these odds ratios. Outcomes show only very subtle differences for bias against nationals from neighbouring countries — which is slightly lower among converted than among immediate respondents—or against nationals from the former Yugoslavia/Albania, which is even slightly higher among converts. The only substantial difference can be observed among the more heterogeneous group of nationals from the remaining countries: while the bias among these foreigners is less than 3 in standard conditions, their odds to be 'converted' are 4 times lower than those of Swiss citizens. All-in-all, these findings highlight that conversion strategies increase the gap between nationals from Switzerland or one of its neighbouring countries, on the one hand, and nationals from more remote countries, on the other hand. 


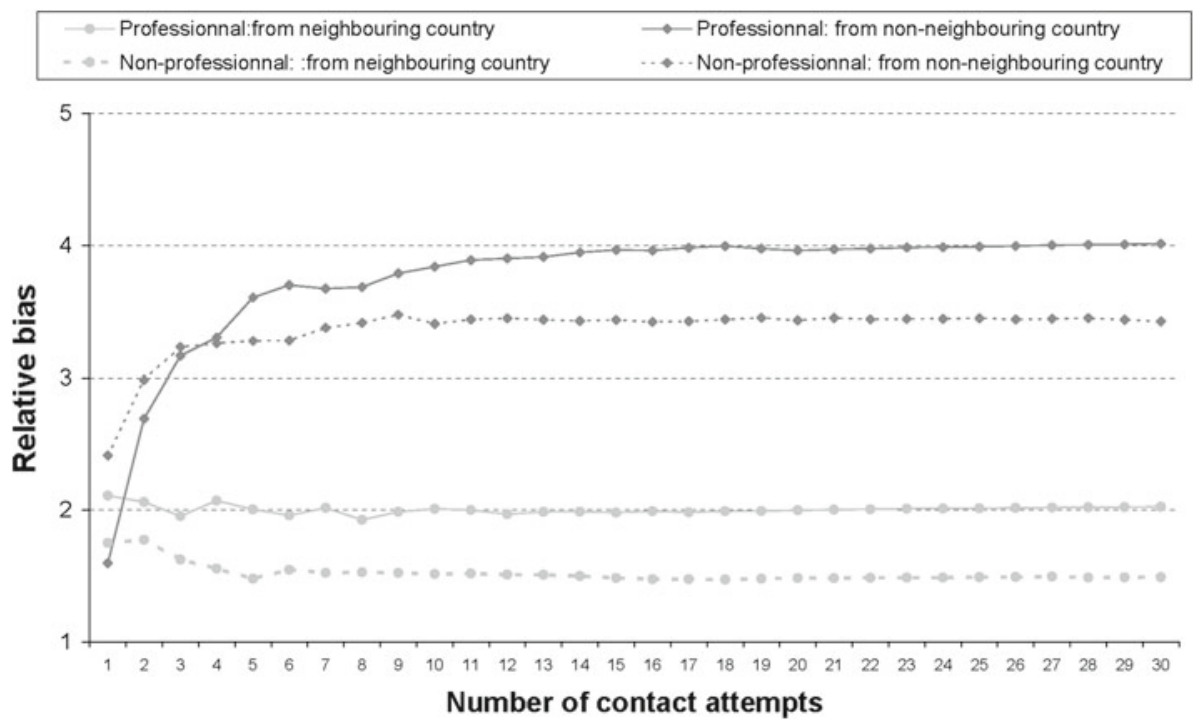

Fig. 4 Estimated relative sampling bias for four waves of ESS in Switzerland (2002-2008), by number of attempts to establish contact or cooperation, and citizenship of target respondents and intervention of professionalised interviewers

Next we addressed Question 2: How does giving priority to more experienced interviewers affect the ability to recruit members from national minorities? Interviewer responses (which are currently available only for the first three waves of the ESS in Switzerland) allowed us to differentiate between those for whom carrying out surveys is their main occupation, on the one hand, from those who work only occasionally or as a secondary occupation as interviewers. We operationally defined an interviewer as falling into the former group of professionalised interviewers when he/she worked more than $50 \%$ (i.e., more than $20 \mathrm{~h}$ a week) as an interviewer, and for more than one year already, at the time of taking part in the fieldwork. As in many cases, more than one individual interviewer intervened in the recruitment chain of one target respondent. In these cases, we defined a recruitment path as affected by professionalised practice when at least one of the first two interviewers that intervened in the chain fulfilled these criteria. Figure 4 displays levels of relative bias (still following Eq. 2) for both types of recruitment chains. In order to keep group sizes large enough for reasonably robust estimates, we had to aggregate nationals from the former Yugoslavia/Albania and nationals from all other countries-which showed greatest similarities in the previous analyses-into one category. The resulting findings are intriguing. They mainly illustrate the fact that professionalised interviewers' higher ability to grant cooperation is largely limited to situations where they interact with Swiss citizens. Ironically, this way interviewers who do perform better with regard to overall response rates (as revealed by other analyses, not reported in detail here), contribute to even higher bias against foreigners from both neighbouring and non-neighbouring countries. More specifically, when professionalised interviewers intervene into longer recruitment chains - more than four attempts to establish contact or cooperationthey will create even higher bias against those minority groups who are already very largely underrepresented (i.e., nationals from non-neighbouring countries). 


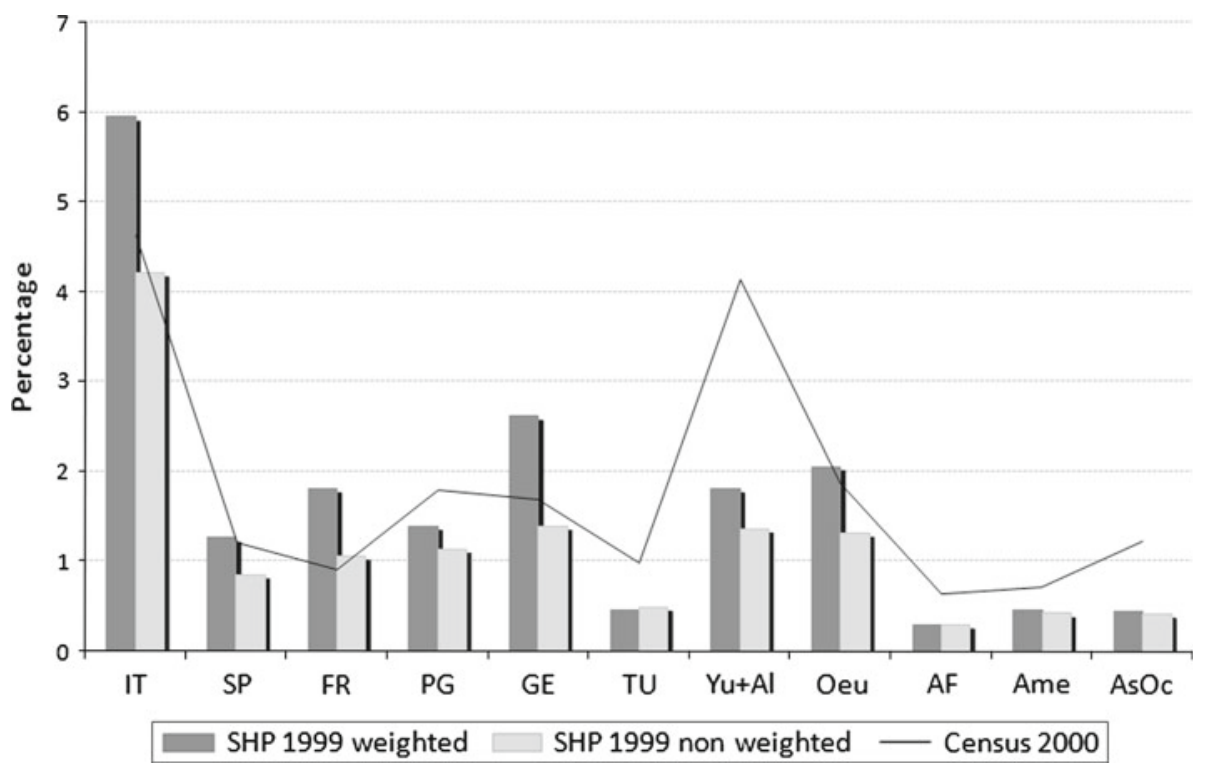

Fig. 5 Representation of national minorities in the SHP weighted and non-weighted compared to Census 2000. IT Italy, SP Spain, FR France, $P G$ Portugal, GE Germany, $T U$ Turkey, $Y u+A l$ Former Yugoslavia and Albania, Oeu Other European country, AF Africa, Ame Americas, AsOc Asia and Oceania

\subsection{Minority bias and survey stratification: evidence from the Swiss Household Panel and Labour Force Survey}

To answer Question 3, we examined the effects of post-stratification adjustment on the representation of national minorities in the SHP and SLFS. For both surveys, cross-sectional post-stratification weights for individuals and households are calculated on the basis of official estimates of the national population's demographic structure. In the SHP, age, nationality, sex, civil status, as well as the seven main geographical regions (by which the sample was stratified) are used to adjust to the known total population of Switzerland (Plaza and Graf 2007, 2008). In the SLFS, the auxiliary variables used were region of residence, marital status, sex, age and nationality. Although in both the SHP and SLFS post-stratification weights were constructed in order to correct for the under-representation of foreigners, they were calculated using binary information: Swiss citizen or non-citizen. As a result, these post-stratification weights lead to a correct estimate of the percentage of the overall foreign population in Switzerland. However, these weights are rarely successful in correcting the bias for specific national minority groups. Figures 5 and 6 compare non-weighted and weighted sample and population shares of different national categories for 1999 (in the case of SHP) and 2000 (in the case of SLFS) only, but they illustrate a pattern that we found consistently for all analysed waves of the two surveys, from 1999 to 2007 (SHP) and from 1997 to 2002 (SLFS). These findings reveal that post-stratification weights lead to an over-representation of national minorities from neighbouring countries such as Germany, France or Italy, while other national minorities, notably from former Yugoslavian or Turkish communities, as well as people of African or Asian origin, remain largely under-represented.

The SLFS represents an interesting case to address Question 4, because after 2003 a new sample was introduced within this survey, in addition to the standard sample. This new 


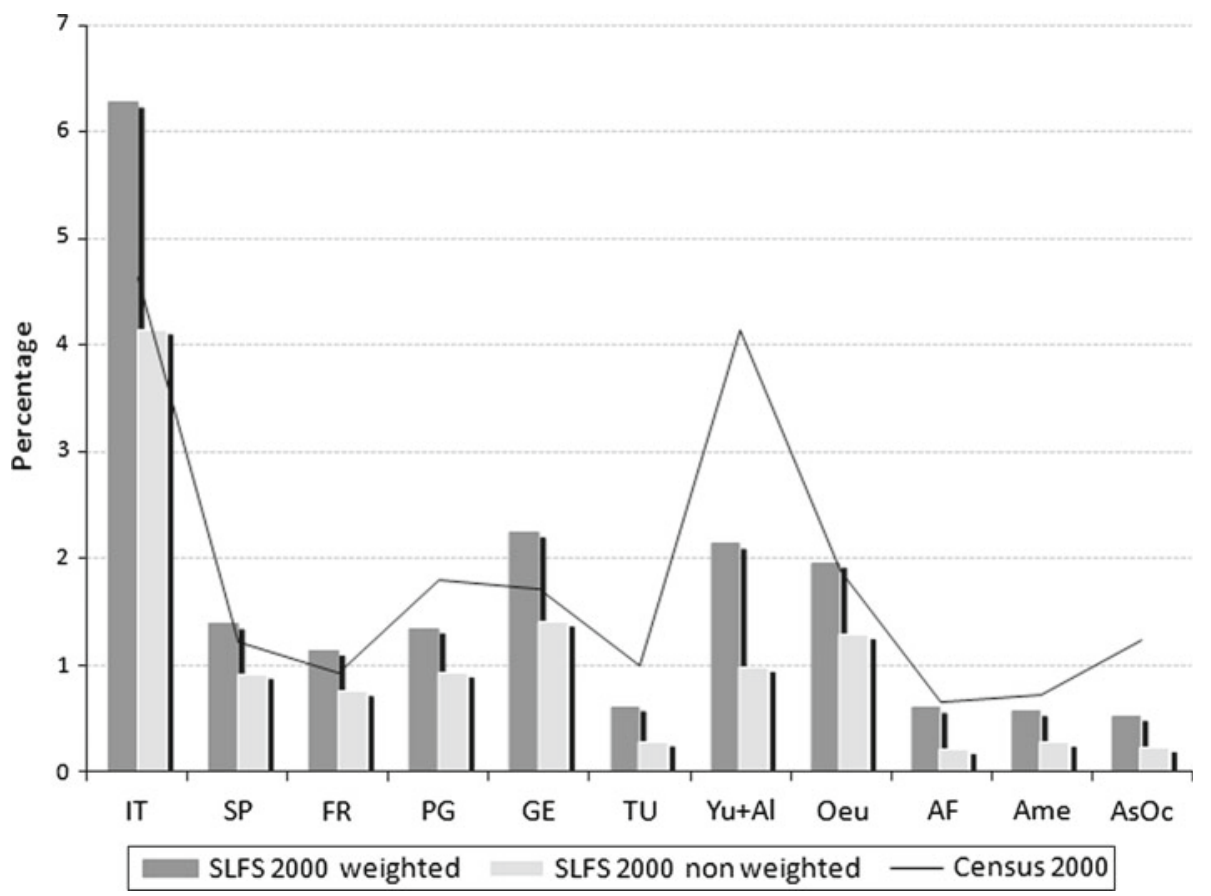

Fig. 6 Representation of national minorities in the Swiss Labor Force Survey weighted and non-weighted compared to Census 2000. IT Italy, SP Spain, FR France, $P G$ Portugal, $G E$ Germany, $T U$ Turkey, $Y u+A l$ Former Yugoslavia and Albania, Oeu Other European country, AF Africa, Ame Americas, AsOc Asia and Oceania

sample — the so-called "SLFS Foreigner" — was stratified, among other things, according to nationality and years of residence in Switzerland. The mixed design hence creates a good opportunity to compare two different sample designs — stratified vs. non-stratified-implemented simultaneously within the same survey. Preliminary checks, which do not need to be reported in detail, confirmed that the national strata have been implemented correctly, i.e., that the (unweighted) share of relevant national categories is equivalent to their share in the population. But, in addition to this obvious consequence of sample stratification, are there any "side-effects" on social bias within national categories? To answer the question, we estimated bias decomposition using the formula that we presented in Eq. 5.

Figure 7 compares within bias estimates and $95 \%$ confidence intervals, ${ }^{2}$ between the non-stratified standard sample and the stratified foreigner sample for 11 national categories and 3 education subcategories separately. These findings suggest that, overall, controlling for minority bias between national categories does not affect bias within national categories: while minority members with middle or high educational levels tend to be well- or over-represented in both samples, members with low educational levels are systematically under-represented, even within the stratified foreigner sample. As a consequence, improvements brought along by stratified survey design still seem to be largely limited to the more

2 Since our checks reported a correct representation of national minorities, we fixed at 0 the between bias and considered only the first term presented in Eq. 5 (that identifies the within bias and correspond to a logarithmic version of Eq. 3). 

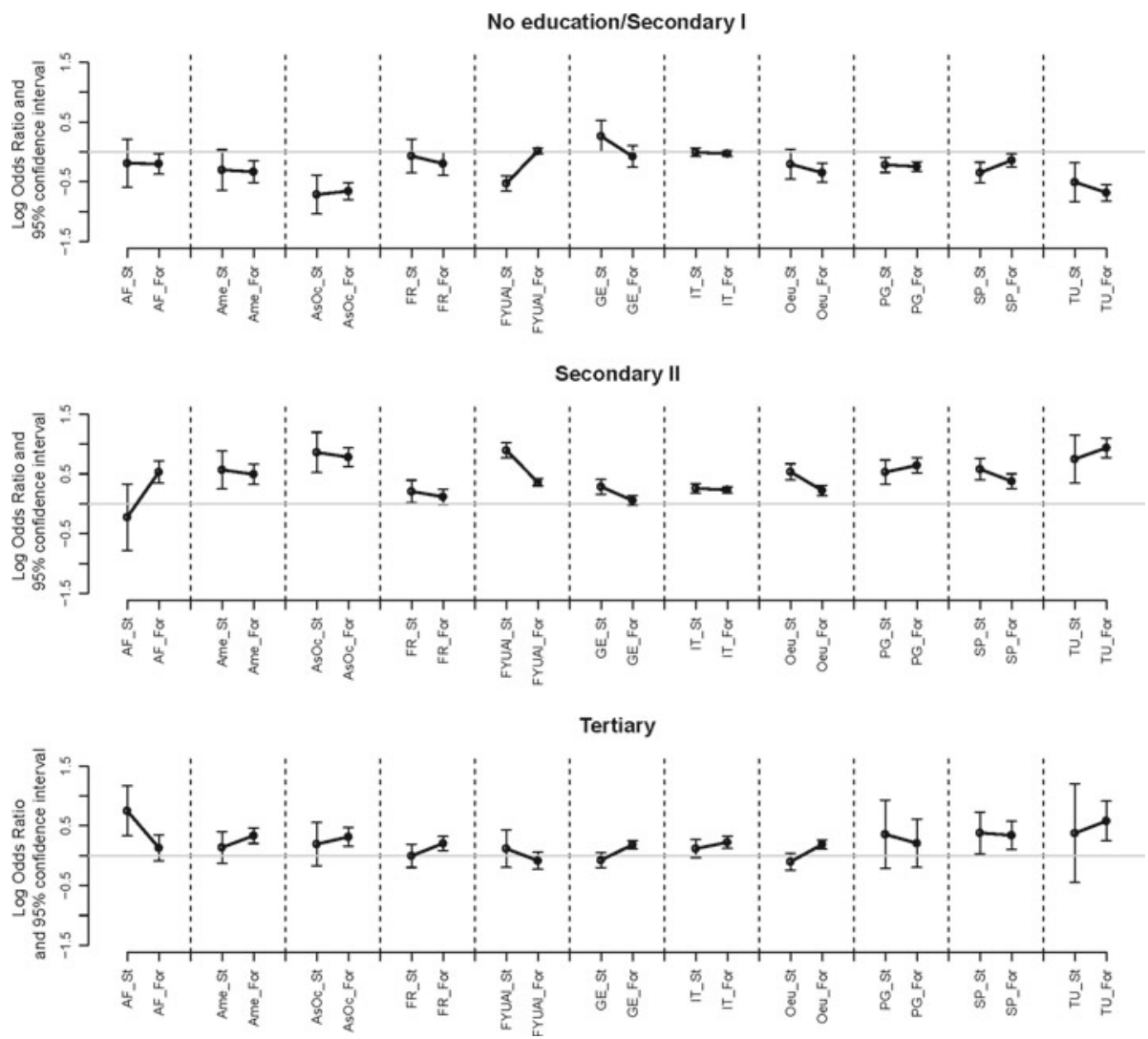

Fig. 7 Estimated within bias and 95\% confidence intervals for national minority groups by educational levels in two National Labour Force Survey samples: SLFS Standard (_St) and SLFS Foreigners (_For) 2003. AF Africa, Ame Americas, AsOc Asia and Oceania, FR France, FYUAL Former Yugoslavia and Albania, GE Germany, IT Italy, Oeu Other European country, PG Portugal, SP Spain, TU Turkey

integrated fractions of national minorities, while a significant bias persists against the most vulnerable parts of these communities.

The main difference in the two samples concerns the precision of the estimates, which is given by smaller confidence intervals in the foreigner sample than in the standard sample, as consequence of a larger sample size. Overall, the use of a stratified sample does not seem to affect the magnitude of the bias. For the most part of national minorities, in fact, the value of bias in the foreigner sample does not significantly differ from the value estimated in the standard sample.

There is one notable exception to this general pattern though: among nationals from the former Yugoslavia or Albania, the under-representation of the least educated and, symmetrically, the over-representation of the most educated, are substantially reduced in the stratified sample, as compared to the non-stratified standard sample. Interestingly, the stratified sample design thus appears to make a difference only for less educated minority members who also benefited from more survey languages (i.e., Serbo-Croatian and Albanian), introduced simultaneously in 2003. However, the interpretation of this finding is complicated by the rotating panel design of the survey: respondents from the stratified sample were all newly 
recruited in 2003, whereas the majority of respondents from the non-stratified standard sample had already been recruited in earlier years, when no additional survey languages had been available. ${ }^{3}$ In the following section, we analyse the impact of survey languages in more detail and try, in particular, to isolate it from the impact of the sample design.

\subsection{Minority bias and the language experiment in the Swiss Labour Force Survey}

When surveys are not offered in the native languages of particular linguistic subgroups, sampled individuals from these subgroups may opt out due to poor understanding of the available survey language(s). To deal with these issues, the SLFS launched a language experiment in 2003. Before that year, the survey was offered only in the three Swiss national languages, German, French, and Italian. In 2003, the SLFS first included the additional languages of English, Serbo-Croatian, and Albanian. To these three languages, Portuguese and Turkish were further added in 2005. According to a methodological report of the SLFS (Widmer 2004), the aim was to reduce as far as possible survey non-participation due to linguistic barriers. In practice however, first contacts with target respondents were still established in one of the three national languages (depending on the region). Interviewers who detected a possible linguistic problem could suggest the possibility of having the survey conducted in English, Serbo-Croatian, or Albanian. If desired by the respondent, the call was then transferred to the appropriate centre. ${ }^{4}$ In $2003,13 \%$ of the SLFS cases in the foreigner sample (2.240 interviews) were conducted in one of these three additional languages. In 2005, with the availability of two new translations, 329 interviews were conducted in Portuguese and 238 in Turkish, while 2.854 interviews were conducted in Serbo-Croatian, Albanian, or English.

To address Question 5 about the impact of language on cross-sectional bias, we compared the between minority bias for the first waves of 2001 and 2002, the first waves of 2003 and 2004 , and the first waves of 2005-2006..$^{5}$ In order to control for changes in the sampling strategy, for both pairs of years after 2003 we used only standard samples. As shown in Fig. 8, the availability of the survey in Serbo-Croatian and Albanian appears to have led to a small increase in participation for members of these national minorities in Switzerland. However, survey representation remained significantly short of population estimates according to 2000 census data $(4.1 \%)$. This suggests that if the bias was reduced, such reduction was not sufficient in order to fill the gap between the census and the survey value. It should be reminded that while speakers of Serbo-Croatian and Albanian form the largest part of the national minority category "ex-Yugoslavian/Albanian", there are others within this group who are not native speakers of Serbo-Croatian or Albanian (e.g., people from Slovenia, Macedonia) and who would not have the language option available to them. Further, during the 2000s there was a slight decrease in the Serbo-Croatian and Albanian population in Switzerland. This could have led to overestimating the bias, given that the real value for 2005-2006 was slightly lower than the 2000 value. A similar, but smaller, increase could be observed two

\footnotetext{
3 To this purpose, it is interesting to notice that the difference between the standard and foreigner sample in the (log) odd ratios for Former-Yugoslav respondent with low educational levels is substantially reduced in 2007 when respondent for both samples could choose to be interviewed in their own or a Swiss national language.

4 While the detail is not present in the methodology report, it is conceivable that some individuals were lost in cases where an immediate transfer to another call centre was not possible at the moment and an interview had to be rescheduled.

5 The SLFS design includes five waves where only individuals in the first wave are interviewed the first time. Therefore the analysis of the bias that considers all the waves in one year risks mixing effect of non-response with effects of attrition. For this reason we consider only the first wave. Additionally, to have a larger sample size, we cumulated the first waves from two following years.
} 


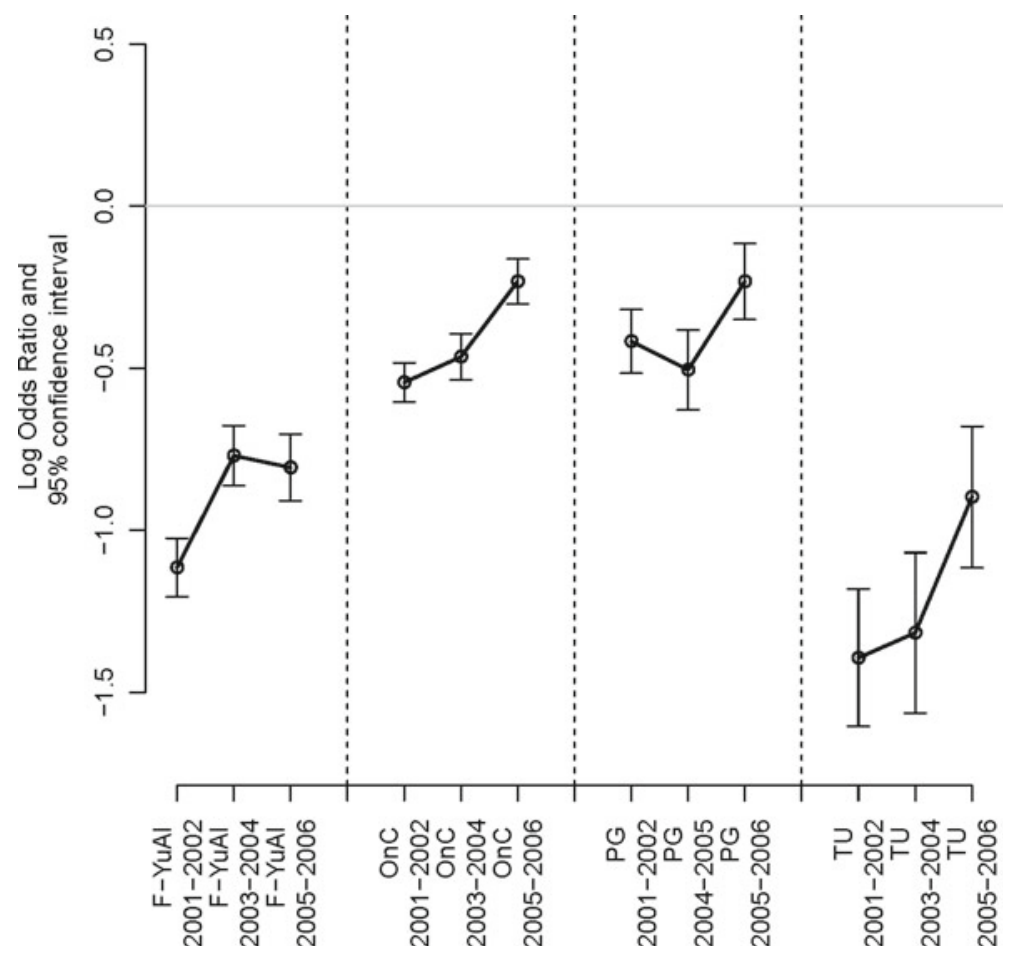

Fig. 8 Estimated between bias and 95\% confidence intervals in three samples of SLFS, before (Sake 20012002) and after the introduction of the questionnaire in English, Serbo-Croat and Albanian (Sake 2003-2004) and Turkish and Portuguese (Sake 2005-2006). Only standard samples from 1 from 1st waves. F-YuAl Former Yugoslavia and Albania, OnC Other non neighbouring country, $P G$ Portugal, $T U$ Turkey

years later for Portuguese and Turkish respondents. Finally, minority bias even disappeared for national minorities from other non neighbouring country, probably as a consequence of the introduction of English as a survey language.

Figure 9 similarly displays the within bias by the level of education over time-still focussing on the non-stratified standard sample. These outcomes reveal a noticeable enhancement in the representation of the least educated former Yugoslavs. As far as Turkish respondents from the same educational category are concerned, findings are ambiguous: their share in the sample decreased immediately after the introduction of Turkish as a survey language 2005, to return to the level previously held, in 2001/2002.

In complementary analyses we wanted to know who actually took the opportunity to be interviewed in another survey language. Figure 10 allows a better understanding of this point. Here we look at the correlates of survey behaviour across different national subgroups: whether they choose a questionnaire in one of the three official languages $(y=0)$ or an additional linguistic version $(y=1)$. All three models presented in this figure have been controlled for gender, age group, duration of stay in Switzerland, household size and area of residence. Further, to have a larger sample size we estimated the models on both standard and foreign samples and introduced a dummy variable to control for the sample membership (SLFS standard vs. SLFS foreigner).

Figure 10 shows that, generally, the lowest educated immigrants are more likely to choose a questionnaire in an additional language. This effect is strongest for Turkish as well as 


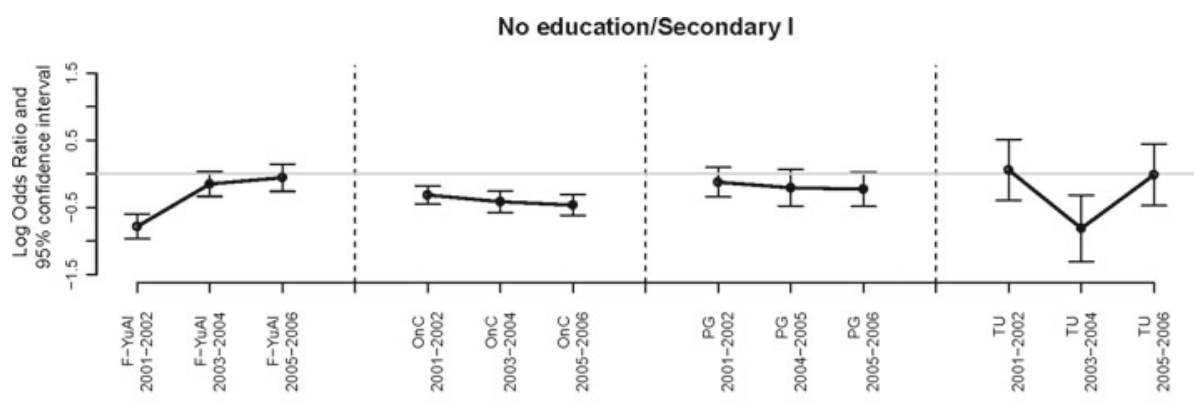

Secondary II

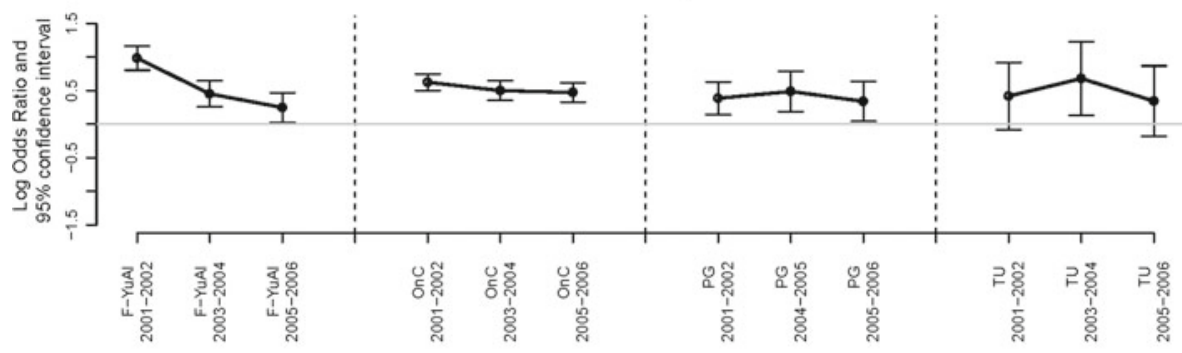

Tertiary

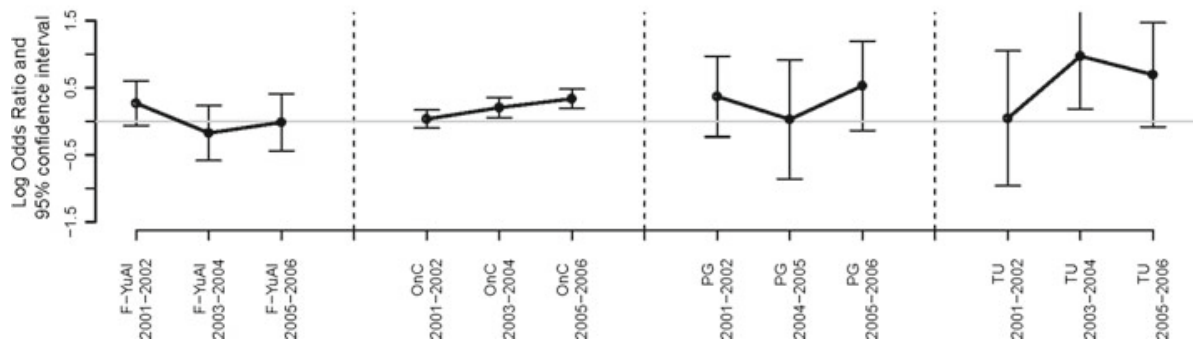

Fig. 9 Estimated within bias by education and nationality before the introduction of questionnaires in language (SLFS 2002) and after the introduction of questionnaires in Serbo-Croat, Albanian, English, Turkish and Portuguese (SLFS 2005). Only standard samples from 1st waves. F-YuAl Former Yugoslavia and Albania, $\mathrm{OnC}$ Other non neighbouring country, $P G$ Portugal, $T U$ Turkey

Ex-Yugoslavian or Albanian respondents with elementary or compulsory education. The effect of social class follows the same direction as education for Turkish, Portuguese and Ex-Yugoslavian/Albanian respondents, but is only significant for the last group.

There is a conundrum here, regarding Turkish and Portuguese respondents from a low educational background: on the one hand, they are numerous to take the offer to be interviewed in their own language, on the other hand, overall, this offer does not appear to facilitate them entering the survey. Does it then at least help them to stay in the survey, once they have been included into the panel?

This leads us to Question 6, the longitudinal variant of the previous question about the impact of linguistic plurality. We addressed this issue by comparing the mechanisms of attrition before and after the increase of linguistic plurality in the SLFS. Two reference periods have been chosen: the years 2001-2002 (before) and the years 2007-2008 (after). Although additional translations were introduced since 2003, the choice of 2007-2008 is owed to two reasons: first, given that Portuguese and Turkish questionnaires were introduced in 2005, in 

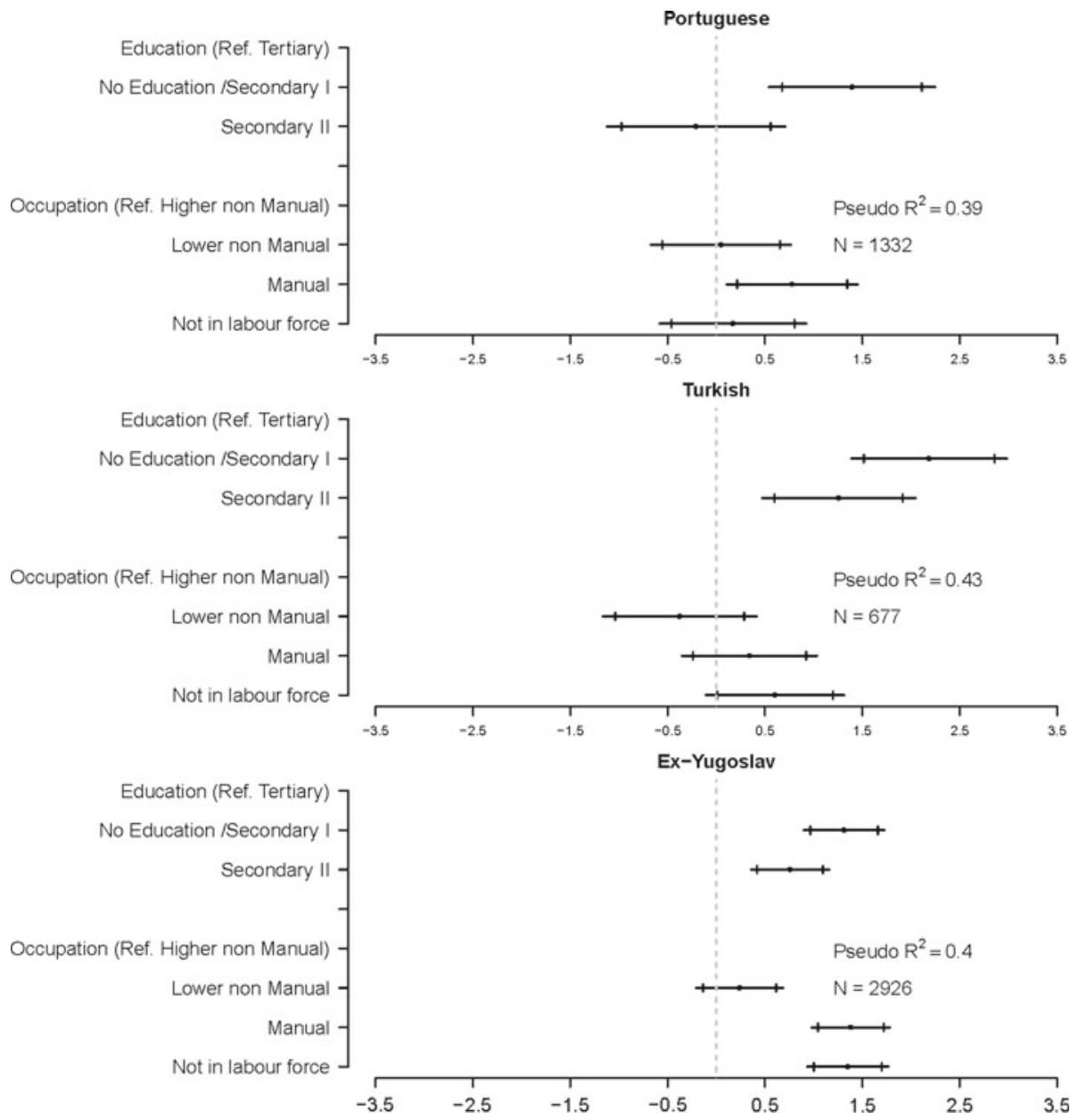

Fig. 10 Coefficients and $95 \%$ confidence intervals from the binomial logistic regression for the probability of choosing translated questionnaire in $(y=1)$ instead of a questionnaire in one of the three Swiss national languages $(y=0)$. Notes: Models controlled for gender, age cohorts, zone of residence, years since migration, wave of interview and sample membership. Source: Our elaboration on Swiss National Labour Force Survey. Year 2008

2007 we can test the effect of questionnaire language on a larger number of groups. Second, using 2007 as comparison year allows having a larger sample size of individuals who had the possibility to use the translated questionnaire since their first presence in the SLFS panel.

The mechanisms of attrition are examined by the use of binomial logistic regression. In all the models the dependent variable takes the value 1 if the subject dropped from the panel and 0 if s/he was interviewed the next year. In order to distinguish the effect owed to the introduction of the questionnaire from the stratified sample, both models (distinguished among them by the time period) have been estimated on the non stratified standard sample (see Figs. 11 and 12). To capture the net effect of national origin, we controlled for occupation related characteristics such as occupation and labour market status, human capital variables (such as education), for demographic variables (gender, age, household size and region of 


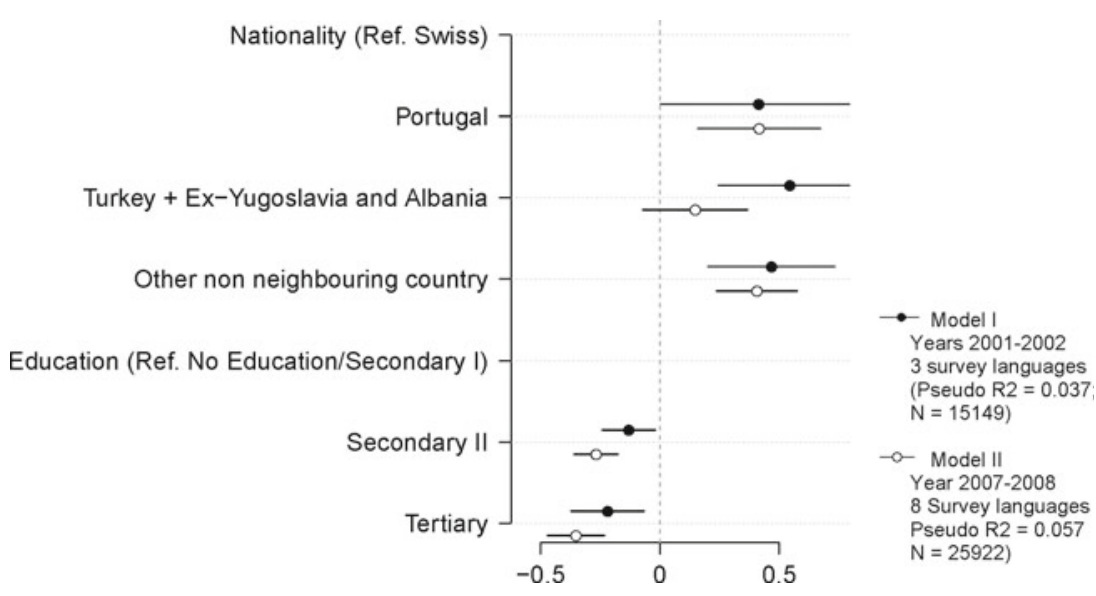

Fig. 11 Coefficients and 95\% confidence intervals from the binomial logistic regression for the probability of attrition $(y=1)$ instead of remaining in the sample $(y=0)$ before and after the introduction of the questionnaire in language. Notes: Model controlled for age-groups, gender, household size, employment status, area of residence in Switzerland, contact attempts and wave of interview. Years: Model I 2001-2002: all sample, Model II 2007-2008: standard sample

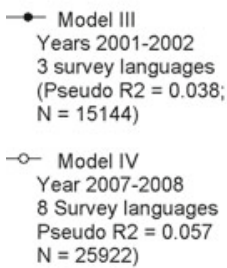

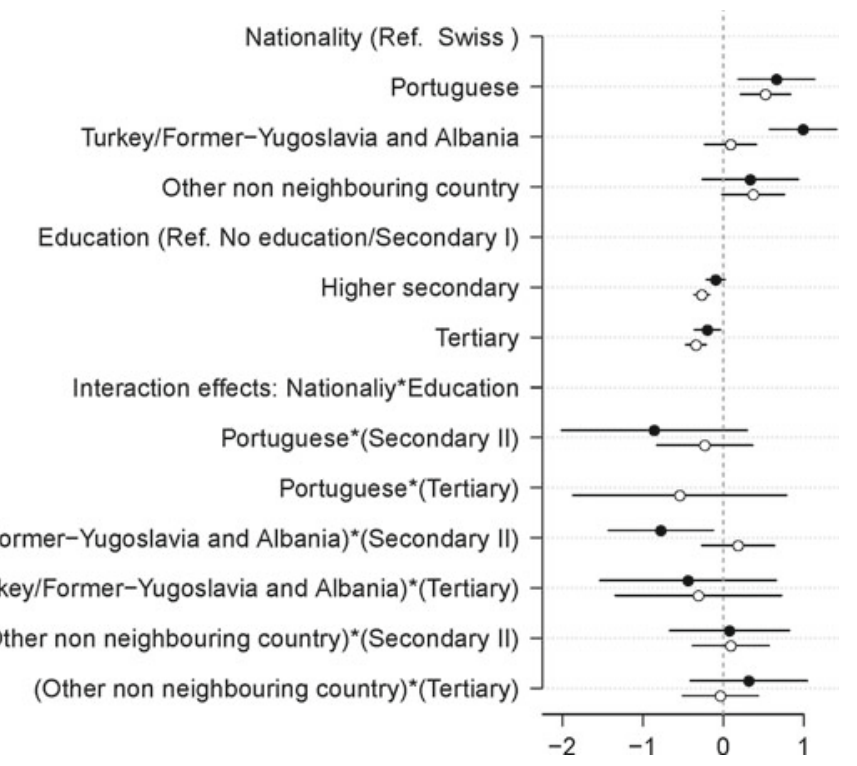

Fig. 12 Coefficients and 95\% coefficient intervals from the binomial logistic regression for the probability of attrition $(y=1)$ instead of remaining in the sample $(y=0)$ before and after the introduction of questionnaire in different languages: interaction effects. Notes: Model controlled for age-groups, gender, household size, employment status, area of residence in Switzerland, contact attempts and wave of interview. Source: Our elaboration on ESPA data, Model III 2001-2002: all sample, Model IV 2007-2008: Standard sample

residence) and for variables related to the survey settings (wave, number of contact attempts). The models have been estimated only for those groups for whom a translated questionnaire was available. If we consider the trends of the coefficients related to the national categories before (model 1) and after the introduction of survey languages (model 2), we notice that after the increase of linguistic plurality for former Yugoslavians/Albanian or Turks, the risk 
of attrition is no more significantly different from the risk of Swiss respondents. The risk of attrition is also reduced for other categories such as minorities from Other non neighbouring countries for which no specific translated questionnaire was available, except for an English version.

Surprisingly, the high probability of attrition among Portuguese respondents slightly increased after the introduction of Portuguese questionnaires (and even passed the threshold of statistical significance for higher attrition than Swiss respondents, due to shrinking standard errors).

In models 3 and 4 (presented in Fig. 12), we introduced interaction effects between education and nationality. The model for the years 2001/2002 gives results that are similar to those presented in Lipps et al. (2011), indicating a particularly high risk of attrition for Portuguese, Former-Yugoslav and Albanian respondents with low levels of education (and hence, a significant interaction between education and national minority status). The corresponding model for years 2007/2008 reveals a different pattern: after the introduction of additional languages, no significant interaction remains between minority status and educational level, for respondents with former-Yugoslavian/Albanian/Turkish nationality. Altogether, these findings suggest that the introduction of the survey language spoken within these communities completely reduces the differential in attrition rates both between minority and majority categories, as well as within these national minorities. There is thus a striking contrast between the relatively small effects of increased linguistic plurality on minority bias in the initial recruitment of respondents, on the one hand, and the very large effects of the same measures on minority bias on the retention of respondents. Probably this difference is related to the fact that, even if the interview could be in a different language, the first contact was still in an official national language, and respondents could not be reached in their own language unless this first obstacle has been surpassed.

\section{General discussion}

3.1 Drawing the line between counter-productive and promising strategies to face minority bias

Let us first summarise findings with respect to the six research questions that motivated our work:

Question 1: Do additional efforts to establish contact or convert reluctant respondents result in less minority bias?

No. From our analyses, more efforts to reach and recruit respondents within the same survey routines led to including more respondents of the same type. Longer contact chains and attempts to convert reluctant respondents resulted in (even) more minority bias, rather than less.

Question 2: Are more experienced interviewers more capable of reducing minority bias?

No. In the current Swiss survey landscape, interviewer learning processes and incentive structures seem to produce a cumulative advantage in favour of respondents from the national majority. More experience appears to help interviewers to recruit (even) more majority respondents and, in all likelihood, to develop economically rewarding strategies to focus their efforts on such "easy" respondents. It results in more rather than less minority bias.

Question 3: Do institutionalised weighting procedures result in statistical estimates free of minority bias? 
No. In Switzerland, a common procedure consists in adjusting survey data for the cumulative share of all foreigners, merged into a single statistical category. This results in the over-representation of immigrants from close and economically prosperous sending countries, while the remaining immigrant communities are still largely underrepresented. As a plausible consequence, weighted statistical estimates remain largely conservative-and difficult to interpret-indicators regarding the situation of vulnerable populations.

Question 4: Does the correction of bias between national categories, by way of stratified sampling, also affect bias within national categories (either positively or negatively)?

Probably not, but it might depend on the overall survey context. The larger part of the evidence suggests that sampling with national strata is neutral with regard to bias within national minority groups. But in combination with more linguistic plurality, it might also have positive effects on the representation of socially disadvantaged groups within national categories. We still need more evidence on possible desirable spill-over effects, but it is safe to dismiss counter-productive side effects.

Question 5: Do additional survey languages help to recruit members from minority groups, in particular among the socially disadvantaged?

Yes, but only to a limited extent. It seems that as long as first contacts are still established in national languages, this might remain a critical obstacle to enhancing the representation of minority communities overall, and of the socially disadvantaged within these communities, in a more consequential way.

Question 6: Do more survey languages help to keep (socially disadvantaged) members from minority groups in the sample or longitudinal studies?

Yes. Once minority respondents have been included in a panel study, they are as likely as majority respondents to remain in, provided that they can be interviewed in their own language. This is true for socially disadvantaged as well as for other minority members.

Overall, these findings suggest that great caution should be exercised with regard to the way (additional) resources are invested in survey research. As long as they are used to do more of the same, it is very unlikely that we will be able to overcome minority bias. And as long as our surveys are biased against national minorities, we cannot expect that official statistical indicators will be able to tell the full story about the scope and human cost of phenomena like social inequalities, precariousness or poverty. A simple rule of thumb can be derived from the insights gained here: The more there is an ethnic cleavage involved in a given social problem (in the direction of a disadvantage for ethnic minorities), the more we are likely to underestimate the problem.

These findings also instruct us that survey quality is not one-dimensional, but that there can be conflicts between different prescriptions, e.g., between overall high response rates and low minority bias. The important lesson to learn is hence that survey strategies are not right or wrong per se, but in relation to specific goals. If these goals prioritise having an appropriate picture of minority groups, standard methodological guidelines are not enough. The cost-effectiveness of specific measures, such as more linguistic plurality, can only be assessed with regard to clearly defined research priorities.

Future research on minority bias should now ideally move from descriptive to experimental research on survey practices. To avoid the pitfalls of the more-of-the-same routines, we need to be creative: to try out and assess alternative survey practices, including different hiring, training, and incentive schemes for interviewers, multi-lingual contact procedures, as 
well as multi-stratified sampling strategies that are based on sociological theory about relevant social cleavages and communities. A critical resource for implementing such sampling strategies can be a general population register (as it is available in Switzerland since October 2010). Register-based sampling frames allow for a better coverage of specific types of hardto-reach populations (e.g., that are not included in telephone register data) and can provide the required information on individuals to stratify the sample by theory-driven criteria. At the same time, we need to broaden the research question from which practices make a difference to how practices make a difference-which implies integrating a more ethnographic component into the way we look at the impact of these factors on the quality of interactions between interviewers and respondents. For example, effective survey processes are likely to rely on a series of implicit assumptions about seemingly trivial things like residential arrangements and daily routines, meaningful interactions and legitimate requests, relevant incentives and appropriate behaviour. Cumulative experiences of survey researchers and interviewers might have well calibrated these assumptions, and the practices they inform, for the majority of the population. Nevertheless or even precisely for this reason - the same set of assumptions can be rather disconnected from the social reality experienced by various minority groups within the same population.

\subsection{Can the study of minority bias in surveys help to understand the broader dynamics} of ethnic exclusion?

The present work and findings may lead to a scientific crossroad, where an interest in survey methods meets a substantive interest in processes that create, reproduce, or reduce social separation between national majority and minority communities more generally. As a matter of fact, these outcomes lead us to reflect critically on the way in which practices that result in exclusion of certain minority groups from participation in surveys are themselves embedded in much wider social practices, which similarly result in the exclusion of the same groups from other fields of social participation. In a context of pervasive public discourse on socalled "immigration" or "integration" issues, there is an understandable public expectation that social scientists should help to develop a clearer understanding of the social dynamics at stake. In this light, it is unfortunate that to date we can only admit [on the basis of the findings reported here, as well as in Lipps et al. (2011)] that major social surveys currently do not help much to get a more accurate picture of the living circumstances, concerns, or aspirations of key minority communities in the country: the available data are not only particularly sparse (with the notable exception of the SLFS foreigner sample that started in 2003), they are also distorted in ways that we only start to understand.

But if the outcomes of these surveys do not yet very much enlighten the social reality of certain minority groups, a closer look at processes that produced these outcomes does shed an interesting light on certain facets of the relations between majority and minority communities. If we aim to understand how the fate of certain communities can be put out of public sight-i.e., excluded from the way the national community represents itself in national statistical indicators - even without a purposeful strategy to achieve such an outcome - there is an opportunity to take here: to start in our own backyard and study the dynamics of community segregation in the production of survey-based evidence. Such an approach also changes the focus of our interest from individuals to interactions, regarding non-participation in surveys as well as in other forms of social interaction. As long as we think about survey nonresponse as being only about the attributes of (non-) respondents (their motivation, skills, or availability), we are indeed likely to think the same about overall social disconnected- 
ness, seen then as a lack of will or capacity to integrate in the host society. But once we start conceiving survey nonresponse as the product of an interaction between interviewers and respondents at a micro-level, and between social researchers and various sub-national communities at a meso-level, we recognise two active parts in the process, and its outcomes become dependent on the overlap of routines, goals, strategies, and assumptions between both parts.

Broadening the theoretical context from minority exclusion in surveys to the social exclusion of minorities more generally goes hand in hand with broadening the geographic context of the phenomena. There is something typically Western-European about the association between "minorities" and "immigration". In this part of the world, more than elsewhere, do so-called ethnic minorities stem from relatively recent waves of immigration, and are largely confounded with the non-citizen population-particularly in countries with restrictive naturalisation policies, like Switzerland.

Furthermore, just as Swiss migration policies represent a more pronounced version of a general trend in Western Europe, a similar argument can be made about the (lack of inclusion) of the resulting minority groups in social surveys. National surveys have been found to be biased against ethno-national minorities across most European countries (Deding et al. 2008; Feskens et al. 2006, 2007; Peracchi and Depalo 2006). At the same time, there has been a remarkable increase in social surveys whose boundaries are those of a nation-state. To a certain extent, the relatively recent institutionalisation of international social surveys - of which the ESS, conducted first in 2002, is a perfect example-might, ironically, even have contributed to reinforce this tendency. As a matter of fact, internationally designed surveys are typically implemented nationally: the funding of the fieldwork is national, and so are survey agencies and interviewer networks, the sampling frames and selection procedures, questionnaire versions, and (in case of the ESS) academic supervision of methodological practices.

In that sense, the major social surveys have become part of an institutionalised set of routine practices that take for granted the nation-state as their natural context and provider of resources (and, maybe, even a sense of purpose): methodological nationalism (Wimmer and Schiller 2002) is embedded in the larger banal nationalism that constitutes the unnoticed structuring background of so many of our daily routines (Billig 1995). The most intriguing consequences of current survey routines that we have highlighted here stem from their tendency to implicitly identify the national population with the national majority (and, thereby, to produce national statistics that blur the situation of national minorities). The insights that we have gained from studying the resulting processes therefore also open an interesting perspective to learn more about "minority bias" in a much more general sense.

Acknowledgments The authors would like to thank Lavinia Gianettoni, Oliver Lipps and Alexandre Pollien for their thoughtful comments on the findings presented in this paper and for a series of stimulating discussions on the role of national minorities in Swiss surveys.

\section{Appendix}

See Table 1. 


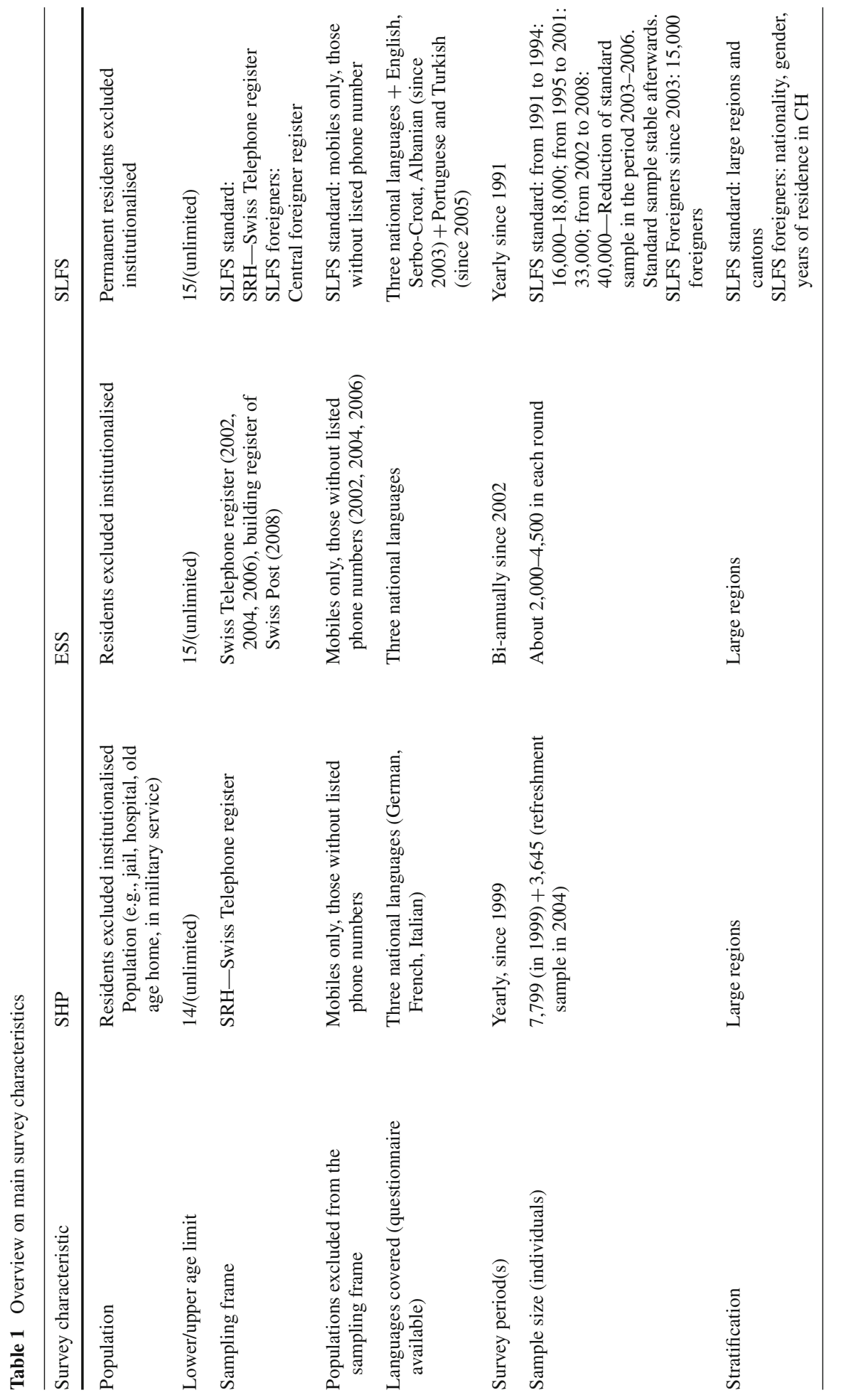




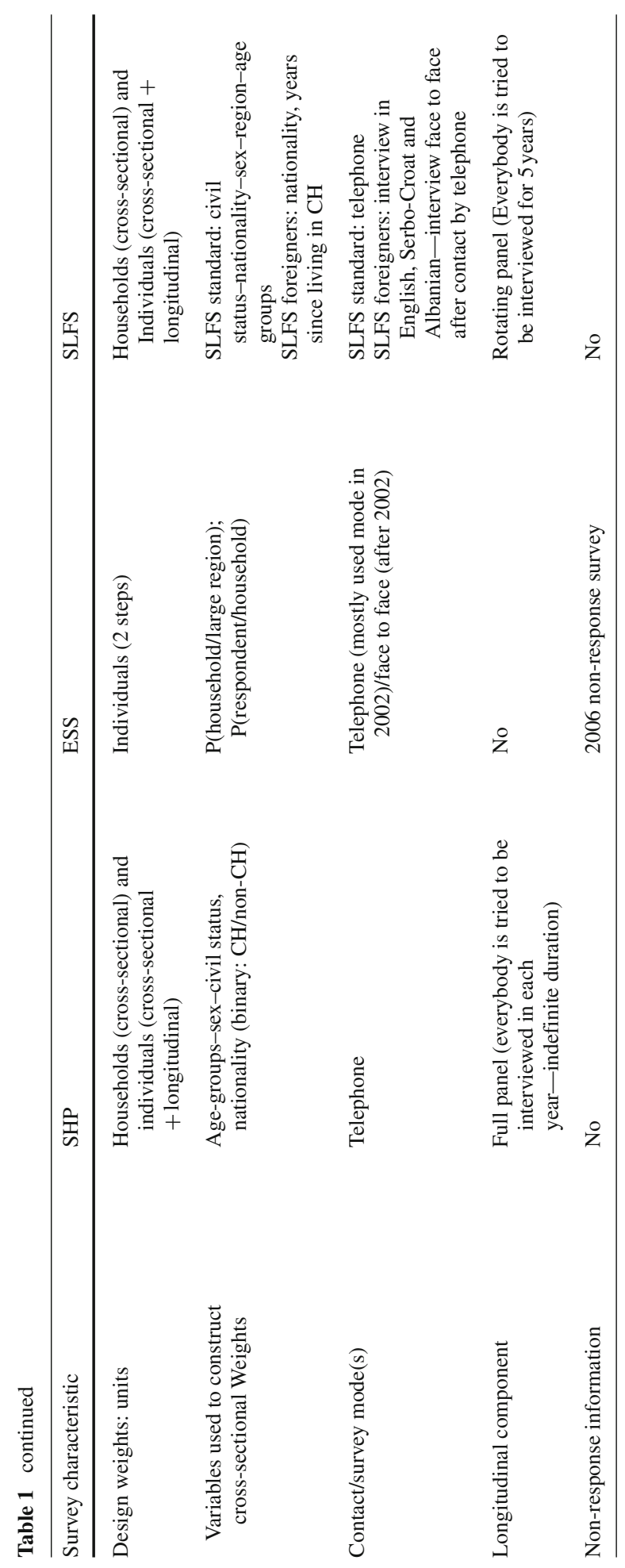




\section{References}

Billig, M.: Banal Nationalism. Sage, London (1995)

Camarota, S., Capizzano, J.: Assessing the Quality of Data Collected on the Foreign Born: An Evaluation of the American Community Survey (ACS). Technical Report, Center for Immigration Studies, Washington (2004)

Castles, S., Miller, J.M.: The Age of Migrations. 2nd edn. MacMillan Press Ltd., Basingstoke (1993)

Deding, M., Fridberg, T., Jakobsen, V.: Non-response in a survey among immigrants in Denmark. Surv. Res. Methods 2(3), 107-121 (2008)

Eisner, M., Ribeaud, D.: Conducting a criminological survey in a cultural diverse context: lessons from the Zurich Project on the social development of children. Eur. J. Criminol. 4(3), 271-298 (2007)

Feskens, R., Hox, J., Lensvelt-Mulders, G., Schmeets, H.: Collecting data among ethnic minorities in an international perspective. Field Methods 18(3), 284-304 (2006)

Feskens, R., Hox, J., Lensvelt-Mulders, G., Schmeets, H.: Non-response among ethnic minorities: a multivariate analysis. J. Off. Stat. 23(3), 387-408 (2007)

Gross, D.: Immigration policy and foreign population in Switzerland. World Bank Policy Research Working Paper 3853 (2006)

Groves, R.M.: Nonreponse rates and nonresponse bias in household surveys. Public Opin. Q. 70(5), 646675 (2006)

Jakobsen, V.: Young immigrants from the former Yugoslavia, Turkey and Pakistan: educational attainment, wages and employment. PhD thesis, Department of Economics, Aarhus School of Business, Aarhus (2004)

Koser, K., Lutz, H.: The new migrations in Europe. Social Construction and Social Realities. MacMillan, London (1998)

Lipps, O., Pollien, A.: Effects of interviewer experience on components of nonresponse in the European Social Survey. Field Methods. 23(2), 156-172 (2011)

Lipps, O., Laganà, F., Pollien, A., Gianettoni, L.: National minorities and their representation in Swiss surveys (I): Providing evidence and analyzing causes for their under-representation. FORS Working Paper Series, paper 2011-2. FORS, Lausanne (2011)

Nielsen, N.K., Pedersen, S.: Databeskrivelse (in Danish). In: Mogensen, G.V., Matthiesen, P.C. (eds.) Integration i Danmark omkring årtusindeskiftet. The Rockwool Foundation Research Unit, University of Aarhus Publisher, Aarhus (2000)

Peracchi, F., Depalo, D.: Labor market outcomes of natives and immigrants: evidence from the ECHP. Social Protection Discussion Paper No. 0615, World Bank, Washington (2006)

Peytchev, A., Baxter, R., Carley-Baxter, L.: Not all survey effort is equal. Reduction of nonresponse bias and nonresponse error. Public Opin. Q. 73(4), 785-806 (2009)

Piguet, E.: L'immigration en Suisse. Cinquante ans d'entreouverture. Presses Polytechniques et Universitaires Romandes, Lausanne (2004)

Plaza, S., Graf, E.: Reccomandations et Exemples Pratiques Concernant l'application des Pondérations. Panel Suisse de Manages, Neuchâtel (2007)

Plaza, S., Graf, E.: Executive summary. Recommendations and practical examples for using weighting. FORS, Lausanne (2008)

Widmer, R.F.: L'enquête Suisse sur la Population Active, Concepts—Bases Méthodologiques, Considérations Pratiques. Office Fédérale de la Statistique, Neuchâtel (2004)

Wimmer, A., Schiller, N.: Methodological nationalism and beyond: nation state building, migration and the social sciences. Glob. Netw. 2(4), 301-334 (2002) 